\title{
Comparing Possible Proxies of Corporate Bond Liquidity ${ }^{1}$
}

\author{
Patrick Houweling ${ }^{2}$
}

Robeco Asset Management

\author{
Albert Mentink ${ }^{3}$ \\ Erasmus University Rotterdam \\ AEGON Asset Management
}

\author{
Ton Vorst ${ }^{4}$ \\ Erasmus University Rotterdam \\ ABN Amro
}

October 29, 2003

\footnotetext{
${ }^{1}$ This paper is a substantially revised version of our earlier paper 'How To Measure Corporate Bond Liquidity?'. We thank Martijn van der Voort, two anonymous referees and participants of the 2003 European Finance Association conference in Glasgow for their constructive comments. Views expressed in the paper are the authors' own and do not necessarily reflect those of Robeco Asset Management, AEGON Asset Management or ABN Amro.

${ }^{2}$ Corresponding author. P.O Box 973, 3000 AZ Rotterdam, The Netherlands; tel: +31-10-244.3538; e-mail: p.houweling@robeco.nl

${ }^{3}$ tel.: $+31-70-344.8177$; e-mail: amentink@aegon.nl

${ }^{4}$ tel.: +31-10-408.1270; e-mail: vorst@few.eur.nl
} 


\section{Comparing Possible Proxies of Corporate Bond Liquidity}

We consider eight different proxies (issued amount, coupon, listed, age, missing prices, yield volatility, number of contributors and yield dispersion) to measure corporate bond liquidity and use a five-variable model to control for interest rate risk, credit risk, maturity, rating and currency differences between bonds. The null hypothesis that liquidity risk is not priced in our data set of euro corporate bonds is rejected for seven out of eight liquidity proxies. We find significant liquidity premia, ranging from 9 to 24 basis points. A comparison test between liquidity proxies shows limited differences between the proxies.

JEL codes:

C13, G12

Keywords:

liquidity, corporate bonds, Fama-French model, euro market 


\section{Introduction}

The effect of liquidity on bond yields has been frequently studied in the recent finance literature. Since liquidity is a rather subjective concept, a lot of measures have been proposed to approximate the extent to which a bond is liquid or illiquid. For corporate bonds, where most transactions occur on the over-the-counter market, direct liquidity measures (based on transaction data) are often not reliable and difficult to obtain. Therefore, researchers resorted to indirect measures ('proxies') that are based on bond characteristics and/or end-of-day prices. This paper makes a number of contributions to this literature on measuring corporate bond liquidity. First, we pay great attention to control for other sources of risk than liquidity to properly identify the premium that is associated with liquidity risk. As far as we know, this is the first study in this strand of the literature to use the well-known Fama and French (1993) two-factor bond-market model to control for interest rate and credit risk and to augment it with individual bond characteristics, such as rating and maturity, as recommended by Gebhardt, Hvidkjaer and Swaminathan (2001). Second, we do not make a subjective choice of which liquidity proxies to work with, but implement as much of the proxies proposed in the literature as possible on our data set. We evaluate the relative performance of all proxies, employing a method recently applied by Goldreich, Hanke and Nathy (2002) on Treasury bonds. Third, the vast majority of empirical papers on sovereign and corporate bond liquidity studied data from the United States and relatively little is known about the extent to which these results apply to the euro market. Although euro corporate bond data were also studied by other authors, including Annaert and De Ceuster (1999), McGinty (2001) and Díaz and Navarro (2002), none of them analyzed the euro corporate bond market using data on individual bonds over a substantial time period.

We use the Brennan and Subrahmanyam (1996) methodology of liquidity-sorted portfolios to test whether liquidity is priced in the euro-denominated corporate bond market. We use eight proxies of bond liquidity: issued amount, coupon, listed, age, missing prices, yield volatility, number of contributors and yield dispersion; see Section 3.4 for a detailed description. For each liquidity proxy, we construct $P$, mutually exclusive portfolios by sorting all bonds on their 
value of the liquidity proxy and assigning the first $100 / P \%$ of the bonds to portfolio 1 , the next $100 / P \%$ to portfolio 2 , and so on, until the last $100 / P \%$ of the bonds are assigned to portfolio $P$. The $P$ time series of portfolio yields are subsequently used in two regression models. In the first model, each portfolio has a constant liquidity premium. In the second model, the liquidity premium is time-varying and a function of the size of liquidity proxy. In both models, the null hypothesis states that the portfolios' liquidity premiums are jointly equal to zero. We use a detailed data set consisting of daily yields of individual corporate bonds which are denominated in euros or in one of the currencies of the euro-participating countries ('legacy' currencies). The results for the first regression model indicate that the null hypothesis of no liquidity premium is rejected for seven out of eight liquidity proxies. So, we find strong evidence of priced liquidity. For the second model the null hypothesis of no liquidity effects is even always rejected. To determine the relative effectiveness of the different liquidity proxies, we run a series of regressions with pairwise combinations of the liquidity proxies, as proposed by Goldreich et al. (2002). This allows us to rank the different liquidity proxies we consider. The results of the tests point out that no proxy stands out from the rest.

The remainder of this paper is structured as follows. Section 2 gives an overview of the methodologies and results of the empirical liquidity literature. Section 3 describes how we control for other sources of risk than liquidity risk and how we estimate the liquidity premium. This section also describes the portfolio construction and our eight liquidity proxies. Next, Section 4 describes the data that are used to test the hypotheses of corporate bond liquidity. Section 5 presents the results from the model implementation. Finally, Section 6 summarizes the paper.

\section{Literature}

Both theoretical and empirical evidence demonstrate that liquidity risk is priced in security markets. The market microstructure models of Amihud and Mendelson (1986), Boudoukh and Whitelaw (1993) and Vayanos (1998) show that transaction costs cause liquidity differences 
between securities, and that illiquid securities have higher expected rates of return than liquid securities.

Empirical evidence on priced liquidity risk in equity markets is provided by, e.g., Amihud and Mendelson (1986), Brennan and Subrahmanyam (1996), Haugen and Baker (1996), Brennan, Chordia and Subrahmanyam (1998), Chordia, Roll and Subrahmanyam (2001) and Chordia, Subrahmanyam and Anshuman (2001). These studies had to cope with an important drawback: they approximated a stock's expected returns by realized returns, which are, by definition, realizations of a stochastic process instead of expectations. For bonds, on the other hand, the yield-to-maturity can be used as expected return measure.

A substantial part of these studies analyzed data from the US Treasury market, where bonds are issued on a regular basis and price data are easily available. Also, controlling for other sources of risk than liquidity risk is relatively easy in this market, because credit risk is not an issue. To control for interest rate risk, authors have used several approaches. The first approach is to create pairs of zero-coupon bonds with exactly the same maturity date; this fully eliminates interest rate risk. Amihud and Mendelson (1991), Kamara (1994) and Strebulaev (2001) used this method to test for liquidity differences between US Treasury notes and bills; Fleming (2002) compared US Treasury bonds with small and large outstanding amounts. The second approach is to form triplets of coupon bonds, which, with suitable bond weights, also eliminate interest rate risk. Elton and Green (1998) used this method to examine yield differences between bonds with high and low trading volume. Another frequently used approach is to analyze the yield difference between the on-the-run (most recently issued) bond and off-the-run (older) bonds; this will, however, leave a small maturity gap between the bonds. Warga (1992), Goldreich et al. (2002) and Krishnamurthy (2002) used this method on US Treasury data and Boudoukh and Whitelaw $(1991,1993)$ on Japanese data. All papers mentioned above, except Strebulaev (2001), found statistically significant liquidity premiums.

Research on corporate bond liquidity is substantially more difficult, because of the presence of credit risk and the smaller number of bonds per issuer. A strategy of matching bonds by maturity 
and issuer, similar to the Treasury studies above, will typically generate too few observations. As far as we know, there is only one study that successfully applied this approach: Crabbe and Turner (1995) analyzed pairs of new issues, issued by the same borrower, with identical issue and maturity dates, but with different issue sizes. The most popular approach is to regress yields (and occasionally bid-ask spreads or trading volumes) of individual corporate bonds on a range of proxies for interest rate, credit and liquidity risk. Examples of studies that used this method include Gehr and Martell (1992), Shulman, Bayless and Price (1993), Chakravarty and Sarkar (1999), Alexander, Edwards and Ferri (2000), Hong and Warga (2000), CollinDufresne, Goldstein and Martin (2001), Ericsson and Renault (2001), Schultz (2001), Díaz and Navarro (2002), Elton, Gruber, Agrawal and Mann (2002) and Mullineaux and Roten (2002). Remarkably, all papers studied US data, except Díaz and Navarro (2002) who studied Spanish corporate bonds. Cornell (1992), Fridson and Jónsson (1995) and Annaert and De Ceuster (1999) used similar regression approaches, but on indices of US mutual funds, US high yield bonds and euro investment grade bonds, respectively. Finally, McGinty (2001) analyzed one month of euro corporate bond data using scatter plots and tables. All papers mentioned above, except for Gehr and Martell (1992) and Crabbe and Turner (1995), found evidence of significant liquidity premiums for at least one liquidity proxy.

To summarize, almost all empirical papers on bond liquidity found significant liquidity effects for government and corporate bonds. However, none of the studies used the portfolio-based testing methodology often employed in the literature on equity liquidity. Moreover, although there is ample research on the US market, the evidence for euro-denominated bonds is limited to papers that study index data (Annaert and De Ceuster, 1999), a small sample period (McGinty, 2001) or data from one country (Díaz and Navarro, 2002).

\section{Methodology}

This section describes the methodology used to test whether liquidity risk is priced in the eurodenominated corporate bond market. First, we explain how we control for other sources of risk 
than liquidity risk using Fama and French (1993) and Gebhardt et al. (2001). Next, we describe the implementation of our models and the Goldreich et al. (2002) method to compare different liquidity proxies. Finally, we present our liquidity proxies.

\subsection{Controlling for Other Sources of Risk}

In measuring a security's liquidity premium, it is important to realize that the security's expected return is not only affected by liquidity risk but also by other sources of risk. Theory (like the reduced form credit risk models following Jarrow and Turnbull (1995)) nominates two risk factors: $(i)$ interest rate risk and (ii) credit risk. We use the Fama and French (1993) bondmarket model as a starting point to proxy for interest rate and credit risk. They found two variables that explained over $90 \%$ of the variation in realized excess returns on corporate bond portfolios; the excess return was defined as the portfolio return minus the one-month Treasury rate. The first risk factor was calculated as the long-term Treasury bond return minus the onemonth Treasury rate at the end of the previous period. Thus, this slope factor should explain variations in excess bond returns by changes in the slope of the Treasury yield curve. The second factor was defined as the return on a market portfolio of long-term corporate bonds minus the long-term Treasury bond return. This credit factor was therefore related to the likelihood of credit events in the corporate bond portfolio.

Unlike Fama and French (1993), we do not us a bond's realized return as proxy for its expected return, but, following the bond liquidity literature, we use the bond's yield-to-maturity. Yields have a distinct advantage over realized returns: they really represent the market's expectation of a bond's expected return to maturity; realized returns are, by definition, realizations of a stochastic process rather than expectations. In all regressions, we thus replace the excess realized return by the excess yield, which is defined as the yield minus the short-term default-free rate.

A second modification to the Fama-French model concerns the choice of the default-free interest rate curve, which is required to calculate the excess yields and the two risk factors. 
Instead of using the government curve, we use the swap curve. Our motivation is that since the end of the 1990s, fixed-income investors have moved away from using government securities to extract default-free interest rates and started using interest rate swap rates instead; see also Golub and Tilman (2000) and Kocić, Quintos and Yared (2000). In Section 5.1, we test both proxies for default-free rates.

Gebhardt et al. (2001) looked at the validity of the Fama-French bond-market model by analyzing whether individual bond characteristics could rival the two Fama-French factors. Three characteristics were considered: rating, duration and Altman (1968) Z-scores. They concluded that both Fama-French factors and bond characteristics were important in explaining bond yields and recommended a model containing four variables: the Fama-French slope and credit factors, rating and duration. In Section 5.2, we show that for our data set a third characteristic is relevant: an indicator variable that equals 1 if a bond is euro-denominated, and 0 otherwise. Therefore, our null model to control for other sources of risk consists of five variables: two Fama-French factors and three characteristics; the model is described formally in Section 3.2. Clearly, all our conclusions about the relation between liquidity and bond yields are based on the assumption that our five-variable pricing model correctly and fully controls for interest rate and credit risk; see also Dimson and Hanke (2001). ${ }^{1}$

To the best of our knowledge, no other paper in the liquidity literature has employed both the Fama-French factors and individual bond characteristics to control for other sources of risk. One paper, Ericsson and Renault (2001), used the Fama-French factors, but not the characteristics; several papers made use of the rating and maturity characteristics, including Alexander et al. (2000), Hong and Warga (2000) and Mullineaux and Roten (2002), but not of the Fama-French factors; most papers used a list of ad-hoc proxies.

\subsection{Models}

Unlike prior papers on bond liquidity, we do not estimate our models on individual bonds, but on constructed portfolios, like in the equity literature; see e.g. Amihud and Mendelson (1986),

\footnotetext{
${ }^{1}$ We further assume that taxes do not affect bond yields.
} 
Brennan and Subrahmanyam (1996) and Haugen and Baker (1996). Specifically, we follow Brennan and Subrahmanyam (1996) by creating liquidity-sorted portfolios and testing whether the constructed portfolios have significantly different expected returns, while controlling for other sources of risk as described above. From the literature, we collect eight liquidity proxies, which are detailed in Section 3.4. For each proxy $i$, we create $P$ mutually exclusive portfolios as follows (the choice for $P$ will be discussed at the end of this section).

Every two weeks, we order all bonds in the sample by their value of liquidity proxy $i$; only bonds that have already been issued and have not yet matured on that date are used in the ordering. Then, we assign the first $100 / P \%$ of the bonds to portfolio 1 , the next $100 / P \%$ to portfolio 2 , and so on, until the last $100 / P \%$ of the bonds are assigned to portfolio $P$. The sort order is chosen such that portfolio 1 contains the bonds that proxy $i$ hypothesizes to be the most liquid and portfolio $P$ the most illiquid. Every day we calculate the yield of each portfolio as the unweighted average of the yields of the bonds that make up the portfolio. A bond's yield is determined as follows: if the bond is not quoted, we disregard it for that day; if it is quoted by one pricing source, we use that yield; if it is quoted by more than one pricing source, we use the average quote. For each proxy $i$, we have now created $P$ time series of portfolio yields.

As in Brennan and Subrahmanyam (1996), the time series are used in two regression models. In the first model, each portfolio has a constant liquidity premium $\alpha_{p}$. Formally, model 1 is as follows

$$
\begin{aligned}
Y_{p t}^{i} & =\alpha_{p}^{i}+\sum_{j=1}^{2} \beta_{j p}^{i} F_{j t}+\sum_{j=1}^{3} \gamma_{j}^{i} C_{j p t}^{i}+\varepsilon_{p t}^{i}, \\
E\left[\varepsilon_{p t}^{i}\right] & =0 \\
E\left[\varepsilon_{p t}^{i} \varepsilon_{q s}^{i}\right] & =\sigma_{p q}^{i}, \text { if } t=s, \text { and } 0 \text { otherwise, }
\end{aligned}
$$

where superscripts $i$ refer to liquidity proxy $i, Y_{p t}^{i}$ is the excess yield of the $p^{t h}$ proxy- $i$ portfolio on day $t, F_{1 t}$ and $F_{2 t}$ are the two Fama-French factors and $C_{1 p t}^{i}, C_{2 p t}^{i}$ and $C_{3 p t}^{i}$ are the three portfolio characteristics. The coefficients are interpreted as follows: $\alpha_{p}^{i}$ is the portfolio-specific 
liquidity premium, $\beta_{j p}^{i}$ is the portfolio-specific factor loading for Fama-French factor $j$ and $\gamma_{j}^{i}$ is the marginal effect of portfolio characteristic $j$. Note that the Fama-French factors have portfolio-specific coefficients and common variable values, while the characteristics have common coefficients and portfolio-specific variable values.

The disturbance terms are allowed to be heteroscedastically distributed and cross-sectionally correlated, but we do assume that they are uncorrelated across time. To correct for possible autocorrelations in the disturbances, we apply the Newey and West (1987) estimator for the covariance matrix. For proxy $i$, we estimate all $3 P+3$ coefficients $\left(\alpha_{1}^{i}, \ldots, \alpha_{P}^{i}, \beta_{11}^{i}, \ldots, \beta_{1 P}^{i}, \beta_{21}^{i}, \ldots, \beta_{2 P}^{i}\right.$, $\left.\gamma_{1}^{i}, \gamma_{2}^{i}, \gamma_{3}^{i}\right)$ for all $P$ portfolios simultaneously with Feasible Generalized Least Squares (FGLS) as a system of seemingly unrelated regressions (SUR); see e.g. Greene (2000, Chapter 15).

To test the null hypothesis that proxy $i$ has no liquidity premium, or in other words, that the two Fama-French factors and the three portfolio characteristics fully explain the bond yields, we use a Wald test to determine the joint significance of the intercepts: $H_{0}: \alpha_{1}^{i}=0 \wedge \ldots \wedge \alpha_{P}^{i}=0$. The test statistic is asymptotically $\chi^{2}$-distributed with $P$ degrees of freedom. ${ }^{2}$

In the second model, we change the functional form of the liquidity premium: all portfolios share a common intercept and a portfolio-specific liquidity variable is added to the regression equation. Formally, regression model 2 reads

$$
Y_{p t}^{i}=\alpha^{i}+\sum_{j=1}^{2} \beta_{j p}^{i} F_{j t}+\sum_{j=1}^{3} \gamma_{j}^{i} C_{j p t}^{i}+\delta^{i} L_{p t}^{i}+\varepsilon_{p t}^{i},
$$

where the definitions of the Fama-French factors, the portfolio characteristics and the assumptions on the disturbances are equal to those in Equation (1) and $L_{p t}^{i}$ is the value of the liquidity proxy of the $p^{t h}$ proxy- $i$ portfolio on day $t$ in deviation from its daily average; so, if $l_{p t}^{i}$ denotes

\footnotetext{
${ }^{2}$ There is caveat in the interpretation of the test results: if we want to test whether proxy $i$ is a good liquidity proxy, we are actually testing a joint hypothesis: illiquidity leads to yield increases and proxy $i$ is a proxy for liquidity; see also Kempf and Uhrig-Homburg (2000) and Jankowitsch, Mösenbacher and Pichler (2002). If we reject this joint hypothesis, then either illiquidity does not lead to yield increases or $i$ is not a good liquidity proxy (or both). Given the strong empirical evidence mentioned in Section 2, we feel confident that a rejection of the joint hypothesis can in fact be traced to $i$ being an inadequate liquidity proxy.
} 
the value of the liquidity proxy, and $\bar{l}_{t}^{i}$ is its daily average, i.e.

$$
\bar{l}_{t}^{i}=\frac{1}{P} \sum_{p=1}^{P} l_{p t}^{i},
$$

then $L_{p t}^{i}$ is calculated as $L_{p t}^{i}=l_{p t}^{i}-\bar{l}_{t}^{i}$. We have chosen this normalization of the liquidity proxy to correct for a possible change in the mean during our sample period. For example, the average amount outstanding has risen from $€ 353$ million on the first day of our sample to $€ 434$ million on the last day.

In Equation (2), the portfolio-specific intercepts of Equation (1) have been replaced by a single intercept and an additional regressor has been introduced that contains a proxy for portfolio $p$ 's liquidity. This changes the functional form of the liquidity premium: the constant liquidity premium of $\alpha_{p}^{i}$ in model 1 has been replaced by a time-varying premium $\alpha^{i}+\delta^{i} L_{p t}^{i}$, that is linear in the value of the liquidity proxy (in deviation from its mean). Here, the null hypothesis of no liquidity effect is tested with a Wald test on the joint significance of $\alpha^{i}$ and $\delta^{i}: H_{0}: \alpha^{i}=0 \wedge \delta^{i}=0$. The test statistic is asymptotically $\chi^{2}$-distributed with 2 degrees of freedom. The joint hypothesis problem discussed above also applies here.

We now discuss the choice for the number of portfolios $P$ for both models. For model 1 , we create two portfolios for each liquidity proxy. This gives an intuitive interpretation of portfolio 1 as the 'liquid portfolio' and portfolio 2 as the 'illiquid portfolio'. Moreover, the difference $\alpha_{2}^{i}-\alpha_{1}^{i}$ between the two intercepts can be interpreted as the yield premium investors get for bearing liquidity risk caused by proxy $i$. In model 2 , we have to estimate the slope coefficient $\delta^{i}$, i.e. the relation between a portfolio's value for liquidity proxy $i$ and its excess yield. Clearly, two portfolios would be insufficient to estimate a slope. However, using 'too much' portfolios diminishes the power of the Wald test; see Lys and Sabino (1992). From their Figure 1, it follows that if the portfolios contain approximately $25 \%$ of the bonds, the power of the test of no relation between the liquidity proxy and the excess yield is maximized. Therefore, we use 4 portfolios for model 2 . 


\subsection{Comparison}

Given the large number of liquidity proxies that have been proposed in the literature, a natural question to ask is whether all proxies are equally suited to proxy bond liquidity or if some proxies work better than others. We follow Goldreich et al. (2002) by running a series of regressions with pairwise combinations of the liquidity proxies. For each combination $(i, k)$ of proxies, we estimate a regression like Equation (2) for proxy $i$, augmented with proxy $k$

$$
Y_{p t}^{i}=\alpha^{i}+\sum_{j=1}^{2} \beta_{j p}^{i} F_{j t}+\sum_{j=1}^{3} \gamma_{j}^{i} C_{j p t}^{i}+\delta^{i} L_{p t}^{i}+\delta^{i k} L_{p t}^{i k}+\varepsilon_{p t}^{i k}
$$

where $L_{p t}^{i k}$ is the value of liquidity proxy $k$ for the $p^{t h}$ proxy- $i$ portfolio in deviation of its daily average. Further, the coefficients are defined and disturbances behave as in Equation (1).

In this regression equation ${ }^{3}$, we test for the significance of $\delta^{i k}$. If it is significant, we say that ' $k$ adds explanatory power to $i$ ', and otherwise we say that ' $k$ is subsumed by $i$ ' (this follows the terminology in Goldreich et al. (2002)). By repeating this procedure for all possible combinations, we can count the number of times a proxy adds power to another proxy, and the number of times a proxy subsumes another proxy. This allows us to rank the different liquidity proxies we consider.

\subsection{Liquidity Proxies}

Empirical papers that examined liquidity in bond or equity markets, used both direct measures (based on transaction data) and indirect measures (based on bond characteristics and/or endof-day prices). Examples of direct liquidity measures are quoted bid-ask spreads, effective bid-ask spreads, quote sizes, trade sizes, quote frequencies, trade frequencies and trading volume. For corporate bonds, where most transactions occur on the over-the-counter market, these direct measures are often not reliable and difficult to obtain. Therefore, we use indirect liquidity proxies

\footnotetext{
${ }^{3}$ Goldreich et al. (2002) first orthogonalized the values of proxy $k$ relative to proxy $i$ and used the orthogonalized values in Equation (3) instead of $L_{p t}^{i k}$. This is not necessary, since, by the Frisch-Waugh theorem (see e.g. Greene, 2000, Section 6.4.3)), the regression already 'automatically' does this for us.
} 
instead. By searching the theoretical and empirical liquidity literature, we found eight liquidity proxies that can be implemented on our data set. ${ }^{4}$ Table 1 shows which papers used which proxies and the effects they found; two proxies, missing prices and yield dispersion, are not mentioned in this table, because they were not used in previous studies. We will now discuss each proxy in more detail, elaborating on their interpretation, their expected effect on bond yields and theoretical and/or empirical evidence.

[Insert Table 1 around here]

\section{Issued Amount}

The issued amount of a bond is often assumed to give an indication of its liquidity. Most investment banks use it as liquidity criterion in building their bond indices; for example, Lehman Brothers uses this criterion for their Euro-Aggregate Corporate Bond index. Its use was first proposed by Fisher (1959), who claimed that large issues should trade more often, so that the proxy issued amount is actually a proxy for the direct liquidity measure trading volume. Since Fisher, several alternative hypotheses have been put forward that also predict a positive effect of issued amount on liquidity (and thus on bond prices). In market microstructure models, like Smidt (1971) and Garman (1976), transaction costs arise, because dealers hold inventories. Further, dealers' inventory costs are higher if it is more difficult to obtain information about a security and if the expected holding time is longer. Crabbe and Turner (1995) subsequently reasoned that large issues may have lower information costs, since more investors own them or have analyzed its features; similarly, information about small issues may be less broadly disseminated among investors. Therefore, small issues will have a higher yield due to an illiquidity premium. Another frequently heard argument, for instance in Sarig and Warga (1989) and Amihud and Mendelson (1991), is that bonds with smaller issued amounts tend to get locked in buy-and-hold portfolios more easily, reducing the tradable amount and thus their liquidity. To summarize the

\footnotetext{
${ }^{4}$ We would like to stress that by selecting liquidity proxies from theoretical research and from empirical research on other data bases, the effects of data-snooping on portfolio-based tests, as described by Lo and MacKinlay (1990), are probably limited.
} 
above, we hypothesize a negative effect of issued amount on yields.

Table 1 shows that many empirical papers considered issued amount as liquidity proxy. The papers on Treasury bonds found negative and mostly significant effects, so that larger Treasury issues have lower yields, as expected. Research on corporate bonds is inconclusive, though: both negative and positive coefficients are observed. McGinty (2001) confirmed this by showing that even though most large issues in his corporate bond sample were liquid, some large issues were illiquid and some small issues were liquid.

\section{Coupon}

Amihud and Mendelson (1991) argued that financial institutions that are constrained to distribute only coupon income on their investments may prefer bonds with higher coupon percentages. This higher demand for high-coupon bonds implies lower yields. On the other hand, coupon is also frequently seen as a proxy for tax effects; see e.g. Shiller and Modigliani (1979): if coupon income is taxed, then bonds with higher coupons will have higher before-tax yields. The predicted sign of the proxy coupon is thus ambiguous.

Few empirical papers employed the proxy coupon; see Table 1. Two papers found an insignificant, positive coefficient, whereas one paper found a significant negative effect.

\section{Listed}

Alexander et al. (2000) reasoned that companies whose equity is listed on a stock exchange must disclose more information than privately held companies. According to the market microstructure models mentioned above, the costs of making a market in bonds of listed firms should thus be smaller. Therefore, we hypothesize that the proxy listed is associated with higher liquidity and lower yields.

Since Alexander et al. (2000) were the only authors to use the liquidity proxy listed, the empirical evidence is limited to their results. Contrary to their expectations, they found that issues of private firms trade more actively and thus are more liquid than issues of listed firms. 
Their explanation of this result was that for private firms debt is the only investment vehicle, while for public firms both debt and equity are traded; therefore, debt of private firms might trade more and have higher liquidity.

\section{Age}

The age of a bond is a popular proxy of its liquidity. Sarig and Warga (1989) observed that as a bond gets older, an increasing percentage of its issued amount is absorbed in investors' buyand-hold portfolios. Thus, the older a bond gets, the less trading takes place, and the less liquid it becomes. Moreover, once a bond becomes illiquid, its stays illiquid until it matures. McGinty (2001) and Schultz (2001) also noted that new issues trade more than old issues. McGinty mentioned lead managers' commitment to making market in the newly issued bond. Schultz pointed out that new issues are typically under priced, so that traders buy bonds after the offering and sell them shortly thereafter. Following these arguments, we hypothesize a positive relation between age and yield.

Empirical research strongly confirms the positive effect of age on yields; see Table 1. This finding holds for corporate and sovereign bonds and for US and European data sets. Moreover, Schultz (2001) found evidence for the argument by Sarig and Warga (1989), since in his sample most bonds were bought and not sold; in other words, the bonds were put in buy-and-hold portfolios.

Market practitioners often use a threshold value to determine if a bond is 'old' or 'young': for some $T$, they mark all bonds with an age smaller than $T$ as 'young' and an age larger than $T$ as 'old'. Some academic papers also use such a dichotomous approach for the liquidity proxy age. For instance, Alexander et al. (2000) set $T=2$ years, Ericsson and Renault (2001) used $T=3$ months, and Elton et al. (2002) employed a threshold value of 1 year. To determine which threshold values give a useful division of bonds, we estimate model 1 from two portfolios, where portfolio 1 contains all bonds younger than $T$ months and portfolio 2 older than $T$ months, for $T=2,4, \ldots, 30$. The difference $\alpha_{2}-\alpha_{1}$ between the portfolio intercepts, i.e. the 
liquidity premium between old and young bonds, and the significance of the Wald test on $H_{0}$ : $\alpha_{2}-\alpha_{1}=0$ are displayed in Figure 1. Thresholds from 4 to 24 months give rise to a significant liquidity premium, while the 2-month threshold and thresholds larger than 24 months do not. All thresholds, except for the smallest of 2 months, yield a significant premium of at least 10 bps. The division between young and old bonds seems to be the strongest for a threshold of 14 months, where the premium equals 36 bps. For the remainder of this study, we arbitrarily use a threshold of 1 year for the proxy age, although any other value between 4 months and 2 years could also be used.

[Insert Figure 1 around here]

\section{Missing Prices}

The occurrence of 'price runs' and missing values is our first liquidity proxy that uses market information. Sarig and Warga (1989) argued that if the liquidity of a bond is sufficiently low, it may happen that on some business days there is virtually no trading in that bond. In their data set, this was recorded as a 'price run': two consecutive prices for a bond were identical. We extend their notion of illiquidity by considering not only the occurrence of a price run, but also the occurrence of a missing value, since in both cases there is no activity in that bond on that day. We will jointly refer to these events as the proxy missing prices. We hypothesize a positive relation between missing prices and yield.

\section{Yield Volatility}

The proxy yield volatility is a measure of yield uncertainty. In the market microstructure models discussed above, dealers' inventory costs are higher if information uncertainty is higher. An important source of uncertainty is related to the predictability of future yield movements. Therefore, we hypothesize that a higher yield volatility leads to larger bid-ask spreads, and thus to lower liquidity and higher yields.

The empirical evidence for yield uncertainty as liquidity proxy is mixed; see Table 1. Shul- 
man et al. (1993) used price volatility as proxy for price uncertainty and found a significantly positive effect on bond spreads. Hong and Warga (2000) proxied uncertainty with squared price return and estimated a positive and significant coefficient in a regression using bid-ask spread as dependent variable; this also implies a positive effect of uncertainty on bond yields. Alexander et al. (2000) approximated uncertainty as the average of absolute price returns; in their regressions, they found a significant, positive effect on trading volume, implying a negative relation between uncertainty and yields.

\section{Number of Contributors}

The number of contributors is our following proxy of a bond's liquidity, and the first that uses quote composition information. In Ericsson and Renault (2001), a larger number of active traders competing for the same bond leads to a smaller price discount for illiquidity and thus a smaller yield premium. Alternatively, Gehr and Martell (1992) and Jankowitsch et al. (2002) argued that a larger number of market participants makes it easier to trade a bond, because it is easier to find a counter party for a transaction and large orders can be split up into smaller parts without affecting the market price. Either way, we hypothesize a positive relation between the proxy number of contributors and liquidity and therefore expect a negative effect of this proxy on bond yields.

Direct empirical evidence on the number of contributors liquidity proxy is limited. Jankowitsch et al. (2002) found that bonds with more contributors have lower yields for all but one of the six European countries they analyzed. Indirect evidence is provided by Schultz (2001), who showed that there was a positive relation between the number of trades in a bond and the number of dealers as counter parties. Further, the results of Gehr and Martell (1992) showed a negative, though insignificant effect of the number of dealers on the bid-ask spread. 


\section{Yield Dispersion}

Our final liquidity proxy, yield dispersion, reflects the extent to which market participants agree on the value of a bond. Tychon and Vannetelbosch (2002) derived a model that predicts that if investors have more heterogeneous beliefs, the liquidity premium is larger. The inventory costs argument, mentioned above, applies here as well, since dealers face more uncertainty if prices show a larger diffusion among contributors. Either way, we hypothesize a positive relation between scatter and bond yields.

We proxy this notion of liquidity with a yield dispersion statistic, which has not been used before in the literature, as far as we know. We define the yield dispersion of bond $b$ on day $t$ as the standard deviation of percentage yield differences relative to the mean

$$
\operatorname{Dispersion}_{b t}=\sqrt{\frac{1}{n_{b t}-1} \sum_{s=1}^{n_{b t}}\left(\frac{y_{b t s}-\bar{y}_{b t}}{\bar{y}_{b t}}\right)^{2}},
$$

where $y_{b t s}$ is the yield quoted by pricing source $s, \bar{y}_{b t}$ is the average yield and $n_{b t}$ is the number of contributors. This proxy can only be calculated if we have at least two quotes for a bond on a particular day, i.e. if $n_{b t}>1$.

\section{Application}

Table 2 gives details on the calculation of each liquidity proxy. It also shows the expected sign of the proxy. To get the $l_{p t}^{i}$ variable of Section 3.2, we multiply proxies with a negative expected sign by -1 . After this transformation, the $\delta^{i}$ coefficient of model 2 is hypothesized to be positive for all proxies; this facilitates checking the results with the hypotheses. Finally, the table shows the order in which bonds are put in the portfolios: the first portfolio always contains the bonds that are hypothesized to be most liquid, the last portfolio contains bonds that we expect to be most illiquid.

[Insert Table 2 around here] 
As described in Section 3.2, every two weeks the portfolios for each liquidity proxy are rebalanced according to each bond's value for that proxy. For the proxies issued amount, coupon, listed (which are fixed characteristics of a bond) and age (which changes only gradually over time), we use the value of the liquidity proxy on the rebalancing date. For the proxies missing prices, number of contributors and yield dispersion (which depend on daily market information), we use the average value over the two weeks prior the rebalancing date. For the proxy yield volatility (which also depends on daily information), we calculate the standard deviation of the observed yields over the two weeks prior to the rebalancing date. If for a particular bond it is not possible to calculate the value of a liquidity proxy on the rebalancing date, that bond is ignored for that proxy until the next rebalancing date.

\section{Data}

The data are downloaded from three different sources. Lehman Brothers provides the International Securities Identification Numbers (ISINs) of the members of their Euro-Aggregate Corporate Bond index. The required characteristics of these corporate bonds are downloaded from Bloomberg. Reuters 3000 EXtra provides daily bid yields of each bond quoted by different pricing sources. The download period starts on 1 January 1999 and ends on 31 May 2001. The ISINs are obtained for 31 May 2000. The total number of bonds on this date equaled 1190 . All bonds that are issued in euros directly after the currency's introduction are included in this analysis. Moreover, the yield time series of each corporate bond has at least twelve months history.

\subsection{Lehman Brothers}

Lehman Brothers provides the ISINs of the corporate bonds in their Euro-Aggregate Corporate Bond index. This index serves as a proxy of the investment-grade euro-denominated, corporate bond market. Lehman Brothers imposes a number of criteria before the corporate bonds can enter its index. All bonds must be denominated in euros or in one of the legacy currencies. 
Further, all bonds are investment grade, have a fixed-rate coupon, at least one-year to maturity and an issued amount of at least 150 million euro. The country of issuance and the country of the issuer are no index criteria. The credit ratings of all corporate bonds are also provided by Lehman Brothers. All ratings are downloaded for 31 May 2000. Due to data limitations, we have kept these ratings unchanged during the whole sample period. Finally, their Euro-Aggregate Corporate Bond BBB sub index is used to construct the Fama-French credit factor.

\subsection{Bloomberg}

Bloomberg provides the required bond characteristics. Using the ISINs that are given by Lehman Brothers these characteristics are downloaded. In case an ISIN code is not recognized by Bloomberg, the bond data are obtained from Lehman Brothers' PC Product system. From the initial 1190 ISINs, three are not available in the Bloomberg data base. The downloaded corporate bond characteristics are: issued amount, issue date, maturity date, currency, call dates, put dates and sinking fund dates. Euro-denominated par swap data, which are used to calculate the two Fama-French factors and the portfolio excess yields, are also downloaded from Bloomberg.

\section{$4.3 \quad$ Reuters}

Reuters 3000 EXtra provides the bid yields of the selected corporate bonds. Most corporate bond yields in the Lehman Brothers Euro-Aggregate index are bid yields; only newly issued corporate bonds have ask yields during their first month in the index; see Lehman Brothers (1999). Therefore, we download bid yields from Reuters. For each corporate bond, all pricing

sources (also called contributors) are downloaded. We exclude two Reuters pricing sources, the clearing agency ISMA and two anonymous pricing sources from the list of contributors, since they are averages of other pricing sources. The total number of different pricing sources thus obtained equals 74 .

From the original 1190 ISINs in the Lehman Brothers Euro-Aggregate Corporate Bond index, 
191 bonds cannot be analyzed, because they either have no Reuters Identification Code (RIC) that matches their ISIN or they do have a RIC but no contributor. For the remaining 999 bonds, all bid yields from all pricing sources are downloaded. This means that a number of time series, equal to the number of pricing sources, shows the yield development of each bond. Most bonds are quoted by more than one pricing source.

\section{Results}

We first present the results of applying the Fama-French bond-market model to the entire sample and show the extension of this model with portfolio characteristics. Next, the regression results for models 1 and 2 are given. Finally, the performance of the liquidity proxies is compared.

\subsection{Entire Sample}

We first test whether the two-factor Fama-French model can be used to describe the average excess yield of all bonds in our sample. This test is relevant, because Fama and French (1993) applied their model to realized returns of US bonds, while we analyze yields of euro-dominated bonds. We estimate the following model

$$
Y_{t}=\alpha+\sum_{j=1}^{2} \beta_{j} F_{j t}+\varepsilon_{t}, \varepsilon_{t} \sim i . i . d .\left(0, \sigma^{2}\right)
$$

where the excess yield $Y_{t}$ is the average bond yield, calculated over all bonds in the sample, minus the one-year euro swap rate, the slope factor $F_{1 t}$ is defined as the ten-year swap rate minus the one-year swap rate of the previous day and the credit factor $F_{2 t}$ is calculated as the Lehman Brothers Euro-Aggregate Corporate Bond BBB sub-index minus the ten-year euro swap rate.

The first row of Table 3 shows the $R^{2}$ and the estimated coefficients along with their $t$ values. The $R^{2}$ value is high and comparable to the values reported by Fama and French (1993). The estimated slope and credit coefficients have the expected positive sign and are strongly 
statistically significant. The intercept is not statistically significant, so that the Fama-French model cannot be rejected for the entire sample.

To test our choice for approximating default-free interest rates with swap rates, regression model (5) is estimated again, but with the swap rates replaced by the government rates. So, the excess yields and the slope and credit factors are now calculated with government yields. Our proxy for euro government rates is the Lehman Brothers Euro-Aggregate Treasury index. The second row of Table 3 shows the regression results. Both the $R^{2}$ and the $t$-values of the slope and credit factors have decreased compared to the model with swap rates. Moreover, the intercept is now significantly different from zero. Therefore, the Fama-French model should be rejected in case government rates are used as default-free rates. This empirically confirms our choice for using swap rates as proxy for default-free interest rates instead of Treasury rates.

[Insert Table 3 around here]

\subsection{Characteristics}

As recommended by Gebhardt et al. (2001), we analyze the added value of incorporating characteristics into the model. We consider three characteristics:

- Rating: rating of the bond's issuer at 31 May 2000: AAA, AA, A or BBB.

- Maturity: the remaining time to maturity of a bond, measured in years.

- Euro: whether a bond is denominated in euros or in one of the legacy currencies. This variable was not used in Gebhardt et al. (2001), who studied US data, but we nevertheless consider it to be relevant for our data set. The motivation is that the market generally sees legacy bonds as less liquid, because these bonds are relatively old, not well known to investors and more difficult to trade due to the legacy currency. ${ }^{5}$

To determine whether a characteristic is important for explaining excess bond yields, we follow the same procedure as for our liquidity proxies, as described in Section 3.2, except that

\footnotetext{
${ }^{5}$ Despite its liquidity interpretation, we do not include the euro characteristic in our list of liquidity proxies, since it is specific to our data set of European bonds just after introduction of the euro. Therefore, it is irrelevant for non-European data sets and for more recent European data sets, since the legacy-denominated bonds will gradually disappear from the market.
} 
the null model is now the Fama-French model of the previous section. For each characteristic $i$, we create portfolios and estimate the following regression model

$$
Y_{p t}^{i}=\alpha_{p}^{i}+\sum_{j=1}^{2} \beta_{j p}^{i} F_{j t}+\varepsilon_{p t}^{i},
$$

where the assumptions on the disturbances are equal to those in Equation (1). For the characteristic rating, we create four portfolios: portfolio 1 contains the AAA-rated bonds, portfolio 2 the AAs, portfolio 3 the As, and portfolio 4 the BBBs. For the characteristic maturity, two portfolios are constructed: portfolio 1 consists of the $50 \%$ shortest bonds, and portfolio 2 of the $50 \%$ longest bonds. ${ }^{6}$ Finally, for the characteristic euro, two portfolios are created as well: portfolio 1 contains the euro-denominated bonds and portfolio 2 the legacy bonds.

The regression results are reported in Table 4. For rating, we find that the intercepts are larger for lower ratings, although the step from AA to A is very small. All Fama-French factor loadings all significant. The Wald test indicates that the four intercepts are jointly highly significant. For maturity, the intercepts of the portfolios reveal that short-maturity bonds have smaller yields than long-maturity bonds, with an average difference of 38 bps. The null hypothesis that the two intercepts are jointly equal to zero is easily rejected. Finally, for euro, the results imply that euro-denominated bonds have smaller yields than legacy bonds, with an average spread of 21 bps between them. Again, the Wald statistic is significant.

[Insert Table 4 around here]

From these results, we conclude that the rating, maturity and euro characteristics are important determinants of excess yield in the euro corporate bond market. To make the characteristics operational, we have to transform them to a numerical scale:

- Rating: the letters are mapped as follows: $\mathrm{AAA}=1, \mathrm{AA}=2, \mathrm{~A}=3$ and $\mathrm{BBB}=4 . \mathrm{Al}-$ though this linearity assumption is somewhat crude, it is not uncommon in the literature. Moreover, since our bonds are all investment grade, and the non-linearities in S\&P's and

\footnotetext{
${ }^{6}$ The portfolios are updated every two weeks, just like in Section 3.2.
} 
Moody's rating scales are especially apparent for speculative grade ratings, we believe that the linear scale is a reasonable approximation.

- Maturity: this is already a continuous variable, and thus needs no transformation.

- Euro: this characteristic is represented by an indicator variable that equals 1 if the bond is denominated in euros, and 0 if it is denominated in a legacy currency.

The value of characteristic $j$ for the $p^{t h}$ proxy- $i$ portfolio on day $t$, denoted $C_{j p t}^{i}$ in Section 3.2, is calculated analogously to the liquidity variable $L_{p t}^{i}$ below Equation (2). For instance, for the characteristic maturity, $C_{j p t}^{i}$ is the average maturity of all quoted bonds in the $p^{\text {th }}$ proxy- $i$ portfolio on day $t$, in deviation from the average maturity of all quoted bonds on day $t$.

\subsection{Model 1}

For the first regression model, Equation (1), we create two portfolios for all eight liquidity proxies. Table 5 contains some summary statistics for these 16 portfolios, averaged over the full sample period of 602 trading days. We observe that the average yields and average liquidity proxies of portfolio 1 (containing the hypothesized liquid bonds) and portfolio 2 (illiquid bonds) are quite different. The yield deviations range from -28 bps (for age) to 8 bps (for number of contributors). Except for the latter proxy, we could prematurely conclude that the liquidity premium is negative, since portfolio 1 has a higher average yield than portfolio 2. However, it is not correct to fully attribute the yield differences to differences in liquidity, since the average maturity and the average rating also vary. Therefore, this table illustrates the necessity of correcting for differences in maturity and rating.

[Insert Table 5 around here]

Table 6 displays the results of estimating model 1 for all liquidity proxies; recall from Section 3.2 that the Fama-French factors have portfolio-specific coefficients and the characteristics common coefficients. All Fama-French factor loadings are statistically significant and have the expected positive sign. The same holds for the coefficients of the rating and maturity characteristics (with one exception: the rating coefficient for issued amount is insignificant). The 
coefficient for the euro characteristic is mostly insignificant, though it does have the expected negative sign for seven out of eight cases. All $R^{2}$-values are around $98 \%$.

Except for the liquidity proxy listed, all intercept pairs are jointly statistically different from zero at a $95 \%$ significance level, as evidenced by the $p$-values of the Wald statistics. This indicates that the remaining seven proxies are indeed able to separate the bonds in our data set into two mutually exclusive portfolios that have statistically different yields, after controlling for differences in maturity, rating and currency. Next we look at the portfolio intercepts themselves. If our hypotheses on the sign of the liquidity effects are correct, the intercept of portfolio 1 should be smaller than that of portfolio 2 for all liquidity proxies. We see that this holds for seven out of eight cases; for listed the order is reversed, but this poses no problem, since the Wald test already indicated that for this proxy the null model cannot be rejected. Further, for the proxy coupon, the results show that low coupon bonds have lower yields than high coupon bonds; this contradicts the liquidity hypothesis of Amihud and Mendelson (1991), but instead supports the alternative interpretation of coupon as tax and/or credit risk proxy.

Another way of looking at the intercepts, is to calculate their differences $\alpha_{2}^{i}-\alpha_{1}^{i}$, which we interpret as the liquidity premium for proxy $i$. The significance of a premium is tested with a Wald test with null hypothesis $H_{0}: \alpha_{2}^{i}-\alpha_{1}^{i}=0$; the test statistic is asymptotically $\chi^{2}$-distributed with 1 degree of freedom. The second to last column of Table 6 shows that the premiums for proxies yield dispersion and age are the largest with 24 bps and 20 bps, respectively, while the premiums for the other proxies are between 9 and 13 bps. All premiums are statistically significant at the $95 \%$ confidence level.

[Insert Table 6 around here]

\subsection{Model 2}

For model 2, we create four portfolios since it maximizes the power of the test for the presence of liquidity effects; see Section 3.2. Unfortunately, this means we cannot conduct the test for proxies listed and age, since they are both binary variables ('listed' versus 'not listed', and 
'young' versus 'old'). The summary statistics for the other six proxies are shown in Table 7. Clearly, the differences between the portfolios are now larger than in Table 5, since we have assigned the bonds to four size percentiles instead of two.

[Insert Table 7 around here]

The regression results are displayed in Table $8 .^{7}$ The Wald statistic that tests for the joint significance of the intercept and the coefficient of the liquidity proxy is statistically significant for all six proxies. So, also using model 2 , we find statistical evidence of the presence of liquidity effects in our data set. The signs of all liquidity coefficients are positive, as hypothesized.

[Insert Table 8 around here]

\subsection{Comparison}

Table 9 summarizes the results of conducting the pair wise comparisons between the liquidity proxies, as described in Section 3.3. For each proxy $i$, we count the number of times it adds power to a model that already contains proxy $j$. We also count the number of times a proxy $j$ is subsumed if it is added to the model of proxy $i$. Looking at the sum of both counts, we see that proxies number of contributors and yield dispersion perform somewhat better than the other four proxies, but the differences are small. Although, the test does not yield a clear winner, we do see that missing prices performs worst of all proxies.

[Insert Table 9 around here]

\section{Summary}

In this paper, we used the Brennan and Subrahmanyam (1996) methodology to test whether bond market liquidity is priced based on several liquidity proxies. Eight proxies were implemented: issued amount, coupon, listed, age, missing prices, yield volatility, number of contributors and yield dispersion. For each liquidity proxy, we constructed mutually exclusive portfolios.

\footnotetext{
${ }^{7}$ The Fama-French factor loadings and the coefficients for the portfolio characteristic are omitted from Table 8 for space considerations.
} 
The time series of portfolio yields were subsequently used in two Fama and French (1993) regression models, augmented with portfolio characteristics as recommended by Gebhardt et al. (2001), to control for differences in interest rate risk, credit risk, maturity, rating and currency between the portfolios. We also conducted pair wise comparisons of the liquidity proxies, as proposed by Goldreich et al. (2002).

The results indicated that the null hypothesis of no liquidity premium should be rejected for seven out of eight liquidity proxies. The premium between liquid and illiquid portfolios depended on the liquidity proxy and ranged from 9 to 24 basis points. The highest premiums were found for the proxies age and yield dispersion. The pairwise comparison tests point out that no proxy stands out from the rest. 


\section{References}

Alexander, G. J., Edwards, A. K. and Ferri, M. G. (2000), 'The determinants of trading volume of high-yield corporate bonds', Journal of Financial Markets 3, 177-204.

Altman, E. I. (1968), 'Financial ratios, discriminant analysis and the prediction of corporate bankruptcy', Journal of Finance 23(4), 589-609.

Amihud, Y. and Mendelson, H. (1986), 'Asset pricing and the bid-ask spread', Journal of Financial Economics 17, 223-249.

Amihud, Y. and Mendelson, H. (1991), 'Liquidity, maturity, and the yields on U.S. Treasury securities', Journal of Finance 46(4), 1411-1425.

Annaert, J. and De Ceuster, M. J. K. (1999), Modelling European credit spreads, Working paper, University of Antwerp-UFSIA.

URL: http://fetew.rug.ac.be/fineco/jana.html

Boudoukh, J. and Whitelaw, R. F. (1991), 'The benchmark effect in the Japanese government bond market', Journal of Fixed Income 1(2), 52-59.

Boudoukh, J. and Whitelaw, R. F. (1993), 'Liquidity as a choice variable: A lesson from the Japanese government bond market', Review of Financial Studies 6(2), 265-292.

Brennan, M. J., Chordia, T. and Subrahmanyam, A. (1998), 'Alternative factor specifications, security characteristics, and the cross-section of expected stock returns', Journal of Financial Economics 49, 345-373.

Brennan, M. J. and Subrahmanyam, A. (1996), 'Market microstructure and asset pricing: On the compensation for illiquidity in stock returns', Journal of Financial Economics 41(3), 441-464.

Chakravarty, S. and Sarkar, A. (1999), Liquidity in U.S. fixed income markets: A comparison of the bidask spread in corporate, government and municipal bond markets, Working paper, Purdue University and Federal Reserve Bank of New York.

URL: http://papers.ssrn.com/sol3/papers.cfm?abstract_id=163139

Chordia, T., Roll, R. and Subrahmanyam, A. (2001), 'Market liquidity and trading activity', Journal of Finance 56(2), 501-530.

Chordia, T., Subrahmanyam, A. and Anshuman, V. R. (2001), 'Trading activity and expected stock returns', Journal of Financial Economics 59, 3-32.

Collin-Dufresne, P., Goldstein, R. S. and Martin, J. S. (2001), 'The determinants of credit spread changes', Journal of Finance 56(6), 2177-2207.

Cornell, B. (1992), 'Liquidity and the pricing of low-grade bonds', Financial Analysts Journal 48(1), 6368.

Crabbe, L. E. and Turner, C. M. (1995), 'Does the liquidity of a debt issue increase with its size? Evidence from the corporate bond and medium-term note markets', Journal of Finance 50(5), 1719-1734.

Díaz, A. and Navarro, E. (2002), 'Yield spread and term to maturity: Default vs. liquidity', European Financial Management 8(4), 449-477.

Dimson, E. and Hanke, B. (2001), The expected illiquidity premium: Evidence from equity index-linked bonds, Working paper, London Business School.

URL: http://phd.london.edu/bhanke/

Elton, E. J. and Green, T. C. (1998), 'Tax and liquidity effects in pricing government bonds', Journal of Finance 53(5), 1533-1562.

Elton, E. J., Gruber, M. J., Agrawal, D. and Mann, C. (2002), Factors affecting the valuation of corporate bonds, Working paper, Stern School of Business, New York University. 
URL: http://pages.stern.nyu.edu/ eelton/Research.htm

Ericsson, J. and Renault, O. (2001), Liquidity and credit risk, Working paper, McGill University and Université Catholique de Louvain.

URL: http://papers.ssrn. com/sol3/papers. cfm?abstract_id=248368

Fama, E. F. and French, K. R. (1993), 'Common risk factors in the returns on stocks and bonds', Journal of Financial Economics 33(1), 3-56.

Fisher, L. (1959), 'Determinants of the risk premiums on corporate bonds', Journal of Political Economy 67, 217-237.

Fleming, M. J. (2002), 'Are larger Treasury issues more liquid? Evidence from bill reopenings', Journal of Money, Credit, and Banking 3(2), 707-735.

Fridson, M. S. and Jónsson, J. G. (1995), 'Spread versus Treasuries and the riskiness of high-yield bonds', Journal of Fixed Income 5(3), 79-88.

Garman, M. (1976), 'Market microstructure', Journal of Financial Economics 3, 257-275.

Gebhardt, W. R., Hvidkjaer, S. and Swaminathan, B. (2001), The cross-section of expected corporate bond returns: Betas or characteristics?, Working paper, Axia Energy Europe, University of Maryland and Cornell University.

URL: http://papers.ssrn. com/sol3/papers.cfm?abstract_id=281209

Gehr, A. K. and Martell, T. F. (1992), 'Pricing efficiency in the secondary market for investment-grade corporate bonds', Journal of Fixed Income 2(3), 24-38.

Goldreich, D., Hanke, B. and Nathy, P. (2002), The price of future liquidity: Time-varying liquidity in the U.S. Treasury market, Working paper, London Business School, Institute of Finance and Accounting. URL: http://phd.london.edu/bhanke/

Golub, B. and Tilman, L. (2000), 'No room for nostalgia in fixed income', Risk (July), 44-48.

Greene, W. H. (2000), Econometric Analysis, 4th edn, Prentice Hall, New Jersey.

Haugen, R. A. and Baker, N. L. (1996), 'Commonality in the determinants of expected stock returns', Journal of Financial Economics 41, 401-439.

Hong, G. and Warga, A. (2000), 'An empirical study of bond market transactions', Financial Analysts Journal 56(2), 32-46.

Jankowitsch, R., Mösenbacher, H. and Pichler, S. (2002), Measuring the liquidity impact on EMU government bond prices, Working paper, Vienna University, CCEFM and Bank Austria.

URL: http://papers.ssrn. com/sol3/papers. cfm?abstract_id=302795

Jarrow, R. A. and Turnbull, S. M. (1995), 'Pricing derivatives with credit risk', Journal of Finance $\mathbf{5 0}(1), 53-85$.

Kamara, A. (1994), 'Liquidity, taxes, and short-term Treasury yields', Journal of Financial and Quantitative Analysis 29(3), 403-417.

Kempf, A. and Uhrig-Homburg, M. (2000), 'Liquidity and its impact on bond prices', Schmalenbach Business Review 52, 26-44.

Kocić, A., Quintos, C. and Yared, F. (2000), Identifying the benchmark security in a multifactor spread environment, Fixed Income Derivatives Research, Lehman Brothers, New York.

Krishnamurthy, A. (2002), 'The bond/old-bond spread', Journal of Financial Economics 66(2-3), 463506.

Lehman Brothers (1999), Introduction to the Pan-European Aggregate Index, Research document, Fixed Income Research. 
Lo, A. W. and MacKinlay, A. C. (1990), 'Data-snooping biases in tests of financial asset pricing models', Review of Financial Studies 3(3), 413-467.

Lys, T. and Sabino, J. S. (1992), 'Research design issues in grouping-based tests', Journal of Financial Economics 32(3), 355-387.

McGinty, L. (2001), 'Issue size versus liquidity in credit', J.P. Morgan Fixed Income Research .

Mullineaux, D. J. and Roten, I. C. (2002), 'Liquidity, labels, and medium-term notes', Financial Markets, Institutions and Instruments 11, 401-423.

Newey, W. and West, K. (1987), 'A simple positive semi-definite, heteroscedasticity and autocorrelation consistent covariance matrix', Econometrica 55, 703-708.

Sarig, O. and Warga, A. D. (1989), 'Bond price data and bond market liquidity', Journal of Financial and Quantitative Analysis 24(3), 367-378.

Schultz, P. (2001), 'Corporate bond trading costs and practices: A peek behind the curtain', Journal of Finance 56(2), 677-698.

Shiller, R. J. and Modigliani, F. (1979), 'Coupon and tax effects on new and seasoned bond yields and the measurement of the cost of debt capital', Journal of Financial Economics 7(3), 297-318.

Shulman, J., Bayless, M. and Price, K. (1993), 'Marketability and default influences on the yield premia of speculative-grade debt', Financial Management 22(3), 132-141.

Smidt, S. (1971), 'Which road to an efficient stock market: Free competition or regulated monopoly', Financial Analysts Journal 27(5), 18-20, 64-69.

Strebulaev, I. A. (2001), Many faces of liquidity and asset pricing: Evidence from the U.S. Treasury securities market, Working paper, London Business School.

URL: http://facultyresearch. Iondon.edu/detwp. asp?id=4952

Tychon, P. and Vannetelbosch, V. (2002), Debt valuation and marketability risk, Working paper, Université catholique de Louvain.

URL: http://www2.econ.ucl.ac.be/Users/v.vannetelbosch/

Vayanos, D. (1998), 'Transaction costs and asset prices: A dynamic equilibrium model', Review of Financial Studies 11(1), 1-58.

Warga, A. D. (1992), 'Bond returns, liquidity and missing data', Journal of Financial and Quantitative Analysis 27(4), 605-617. 
Figure 1: Liquidity premiums for different age thresholds. ${ }^{\dagger}$

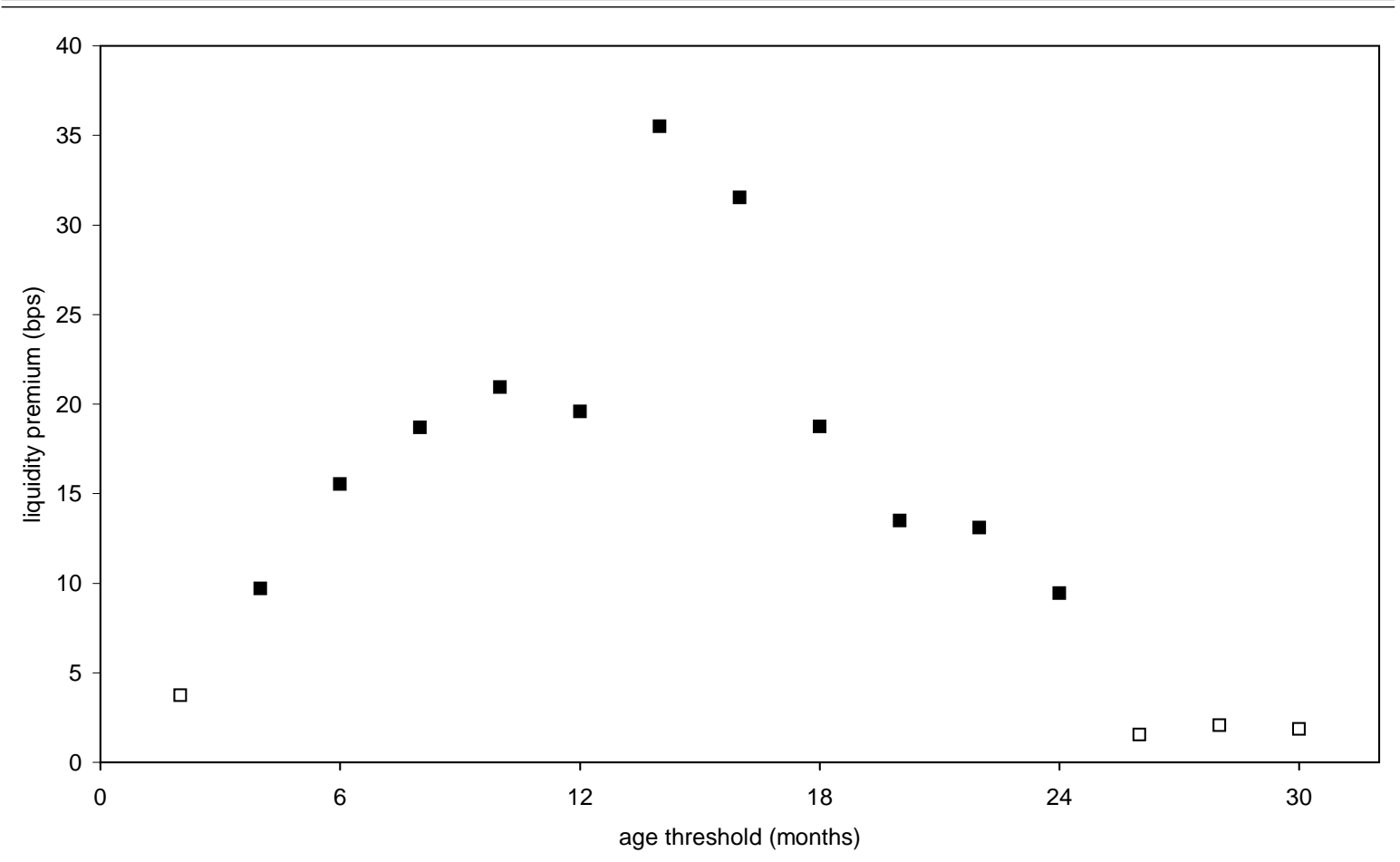

$\overline{\dagger \text { Solid }(\mathbf{\square}) \text { and empty }(\square) \text { squares denote significance and insignificance, respectively, of the Wald test on the }}$ joint significance of the two intercepts $(p$-value $<0.05)$. 
Table 1: Overview of liquidity proxies from the empirical bond liquidity literature. ${ }^{\dagger}$

\begin{tabular}{|c|c|c|c|c|c|c|c|}
\hline \multirow[b]{2}{*}{ Authors $^{a}$} & \multirow[b]{2}{*}{ Data } & \multicolumn{6}{|c|}{ Liquidity proxies } \\
\hline & & $\begin{array}{l}\text { issued } \\
\text { amount }\end{array}$ & coupon & listed & age & $\begin{array}{c}\text { yield } \\
\text { volatility }\end{array}$ & $\begin{array}{l}\text { number of } \\
\text { contributors }\end{array}$ \\
\hline \multicolumn{8}{|c|}{ CORPORATE BONDS } \\
\hline AEF00 & US & $-{ }^{*}$ & & $+^{*}$ & $+^{*}$ & $-{ }^{*}$ & \\
\hline СТ95 & US & $\diamond$ & & & & & \\
\hline EGAM02 & US & $\diamond$ & & & $+^{*}$ & & \\
\hline ER01 & US & & & & $+^{*}$ & & \\
\hline GM92 & US & $++^{\diamond}$ & $+^{\diamond}$ & & & & $-\diamond$ \\
\hline HW00 & US & $-^{*}$ & & & $+^{*}$ & $+^{*}$ & \\
\hline M01 & EMU & $\diamond$ & & & $\diamond$ & & \\
\hline MR02 & US & $+^{\diamond}-\diamond$ & & & & & \\
\hline S01 & US & & & & + & & \\
\hline SBP93 & US & $\diamond$ & & & & $+^{*}$ & \\
\hline \multicolumn{8}{|c|}{ TREASURY BONDS } \\
\hline AM91 & US & & $-^{*}$ & & & & \\
\hline EG98 & US & & & & $+^{*}$ & & \\
\hline F02 & US & $\diamond$ & & & & & \\
\hline JMP02 & $\mathrm{EMU}^{\mathrm{b}}$ & $-{ }^{*}$ & & & & & $-{ }^{*}$ \\
\hline K02 & US & $-^{*}$ & & & & & \\
\hline $\mathrm{KU}^{\mathrm{C}} \mathrm{C}^{\mathrm{C}}$ & Germany & $-^{*}$ & & & & & \\
\hline SW89 & US & - & & & $+^{*}$ & & \\
\hline W92 & US & $-\diamond$ & $+^{\diamond}$ & & $+^{*}$ & & \\
\hline \multicolumn{8}{|c|}{ CORPORATE \& TrEasury BONDS } \\
\hline DN02 & Spain & $+^{*}-^{*}$ & & & $+^{*}$ & & \\
\hline \multicolumn{8}{|c|}{ CORPorate, MUNicipal \& TREASURY BOnds } \\
\hline CS99 & US & & & & $+^{*}$ & & \\
\hline
\end{tabular}

${ }^{\dagger}$ Legend: - negative; + positive; ${ }^{*}$ significant; ${ }^{\diamond}$ insignificant.

a AEF00=Alexander, Edwards and Ferri (2000), AM91=Amihud and Mendelson (1991), CS99=Chakravarty and Sarkar (1999), CT95=Crabbe and Turner (1995), DN02=Díaz and Navarro (2002), EG98=Elton and Green (1998), EGAM02=Elton, Gruber, Agrawal and Mann (2002), ER01=Ericsson and Renault (2001), F02=Fleming (2002), GM92=Gehr and Martell (1992), HW00=Hong and Warga (2000), JMP02=Jankowitsch, Mösenbacher and Pichler (2002), K02=Krishnamurthy (2002), KU00=Kempf and Uhrig-Homburg (2000), M01=McGinty (2001), MR02=Mullineaux and Roten (2002), S01=Schultz (2001), SBP93=Shulman, Bayless and Price (1993), SW89=Sarig and Warga (1989), W92=Warga (1992).

b JMP02 considered 6 countries: Austria, France, Germany, Italy, Spain and The Netherlands.

c We used the price discounts in KU00's Table 2 to calculate the impact of maturity on yields. 


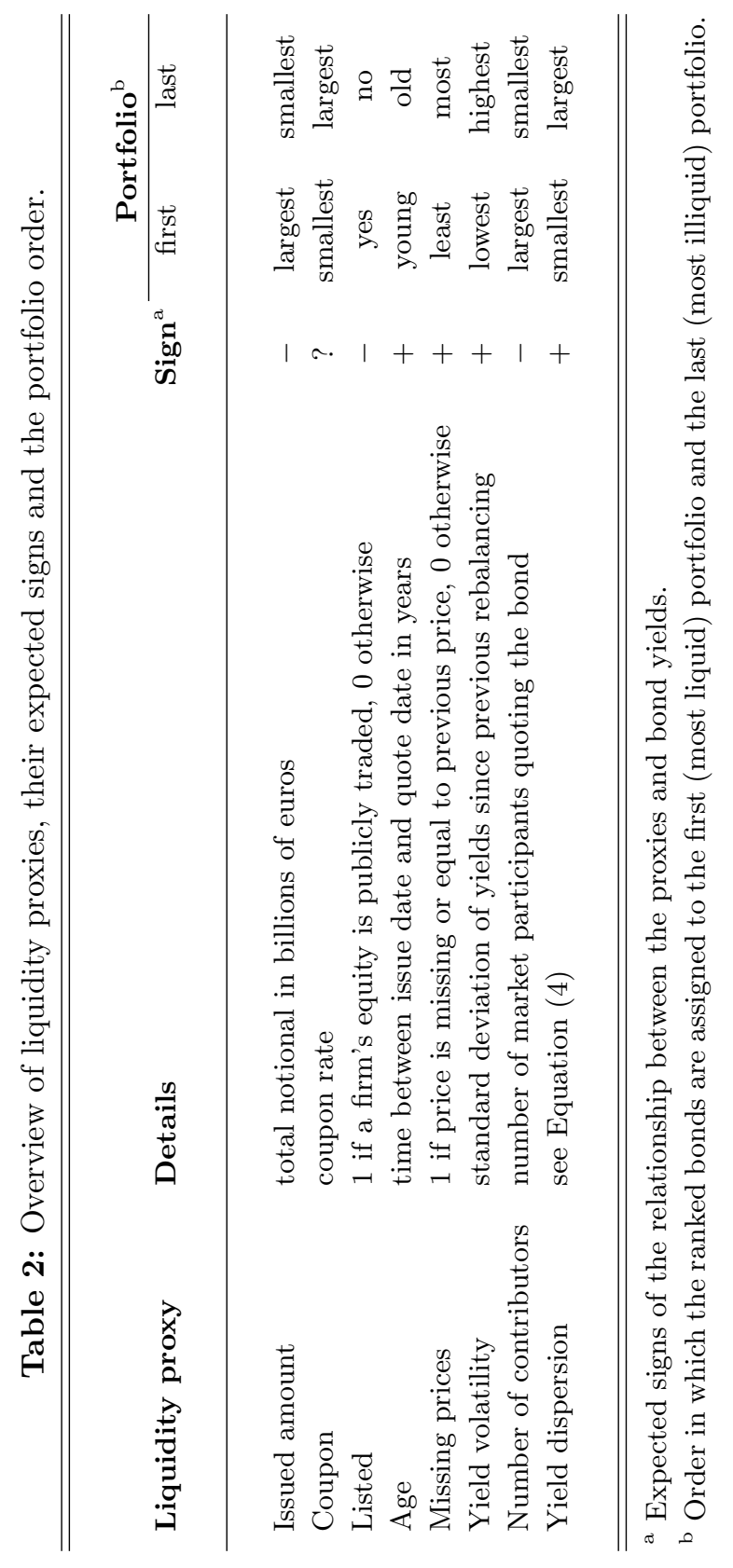


Table 3: Results for the entire sample ${ }^{\dagger}$

\begin{tabular}{|c|c|c|c|c|}
\hline & Intercept & Slope & Credit & $R^{2}$ \\
\hline Swap rates & $\begin{array}{r}0.0371 \\
(1.01)\end{array}$ & $\begin{array}{c}0.785 \\
(36.5)\end{array}$ & $\begin{array}{r}0.173 \\
(6.66)\end{array}$ & $97.9 \%$ \\
\hline Government rates & $\begin{array}{r}0.419 \\
(12.4)\end{array}$ & $\begin{array}{r}0.540 \\
(31.4)\end{array}$ & $\begin{array}{r}0.273 \\
(5.46)\end{array}$ & $95.0 \%$ \\
\hline
\end{tabular}

Table 4: Results for the characteristics portfolios. ${ }^{\dagger}$

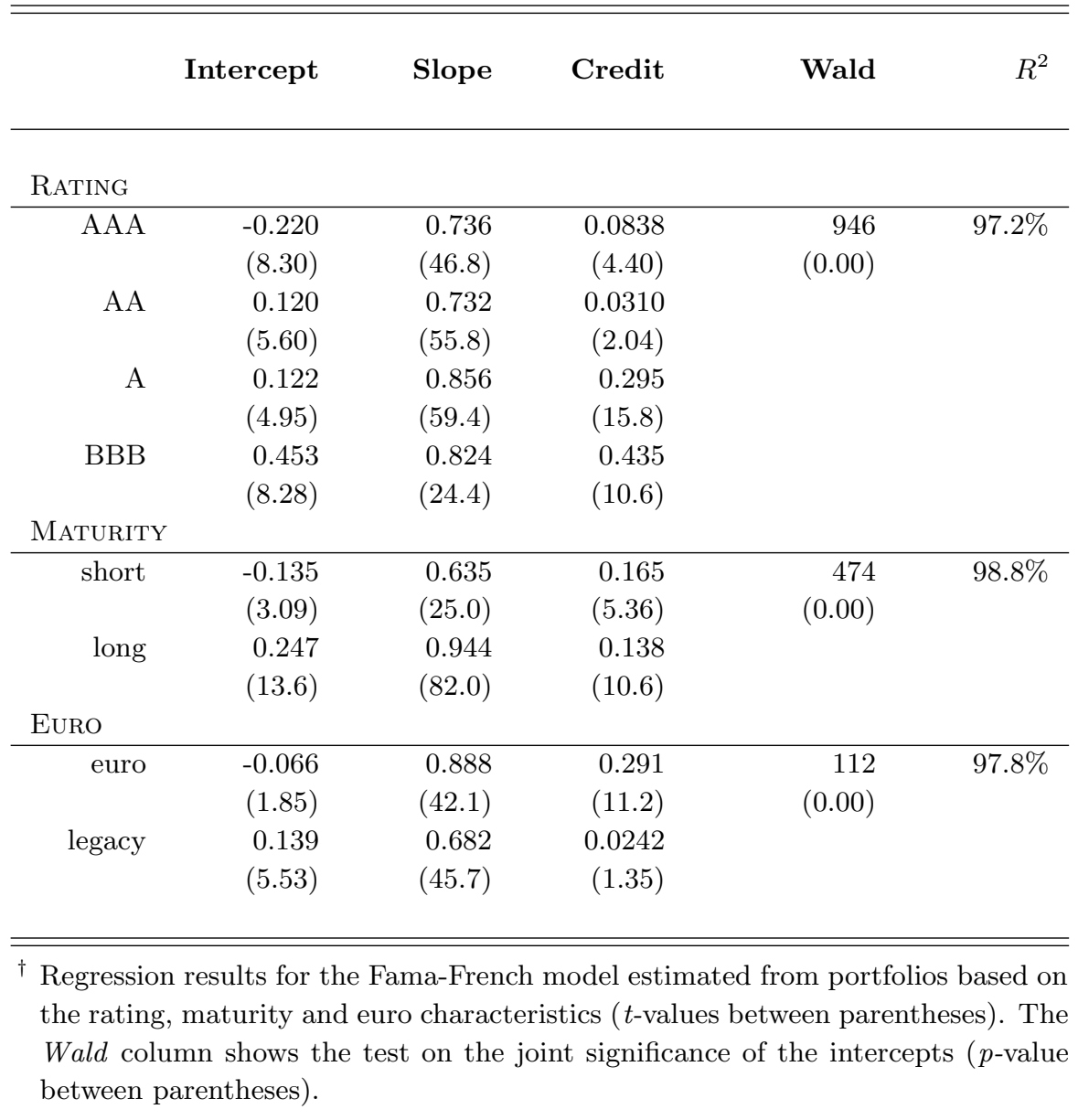


Table 5: Portfolio statistics $P=2 .^{\dagger}$

\begin{tabular}{|c|c|c|c|c|c|c|c|c|}
\hline & \multicolumn{2}{|c|}{ Yield $^{\mathrm{a}}$} & \multicolumn{2}{|c|}{ Maturity $^{\mathrm{b}}$} & \multicolumn{2}{|c|}{ Rating $^{\mathrm{c}}$} & \multicolumn{2}{|c|}{ Liquidity $^{\mathrm{d}}$} \\
\hline & 1 & 2 & 1 & 2 & 1 & 2 & 1 & 2 \\
\hline Issued amount & 5.33 & 5.09 & 6.47 & 4.64 & 2.20 & 2.10 & 0.65 & 0.20 \\
\hline Coupon & 5.21 & 5.21 & 6.05 & 5.04 & 2.14 & 2.16 & 4.29 & 6.91 \\
\hline Listed & 5.26 & 5.01 & 5.68 & 5.11 & 2.27 & 1.66 & 1.00 & 0.00 \\
\hline Age & 5.44 & 5.16 & 6.91 & 5.31 & 2.42 & 2.09 & 0.64 & 3.80 \\
\hline Missing prices & 5.28 & 5.07 & 6.09 & 4.57 & 2.18 & 2.10 & 0.19 & 0.46 \\
\hline Yield volatility & 5.21 & 5.21 & 6.11 & 5.06 & 2.10 & 2.20 & 0.06 & 0.10 \\
\hline Number of contributors & 5.19 & 5.27 & 5.58 & 5.56 & 2.13 & 2.19 & 2.31 & 0.76 \\
\hline Yield dispersion & 5.40 & 5.14 & 7.42 & 4.91 & 2.18 & 2.13 & 0.47 & 1.50 \\
\hline
\end{tabular}

$\dagger$ Summary statistics of the two constructed portfolios using the eight liquidity indicators. Portfolio 1 (respectively 2) contains the bonds that are hypothesized to be most liquid (respectively most illiquid).

a Average portfolio yield.

b Average time to maturity in years.

c Average credit worthiness, measured on the following scale: $\mathrm{AAA}=1, \mathrm{AA}=2, \mathrm{~A}=3$, $\mathrm{BBB}=4$.

d Average value of the liquidity proxy. 


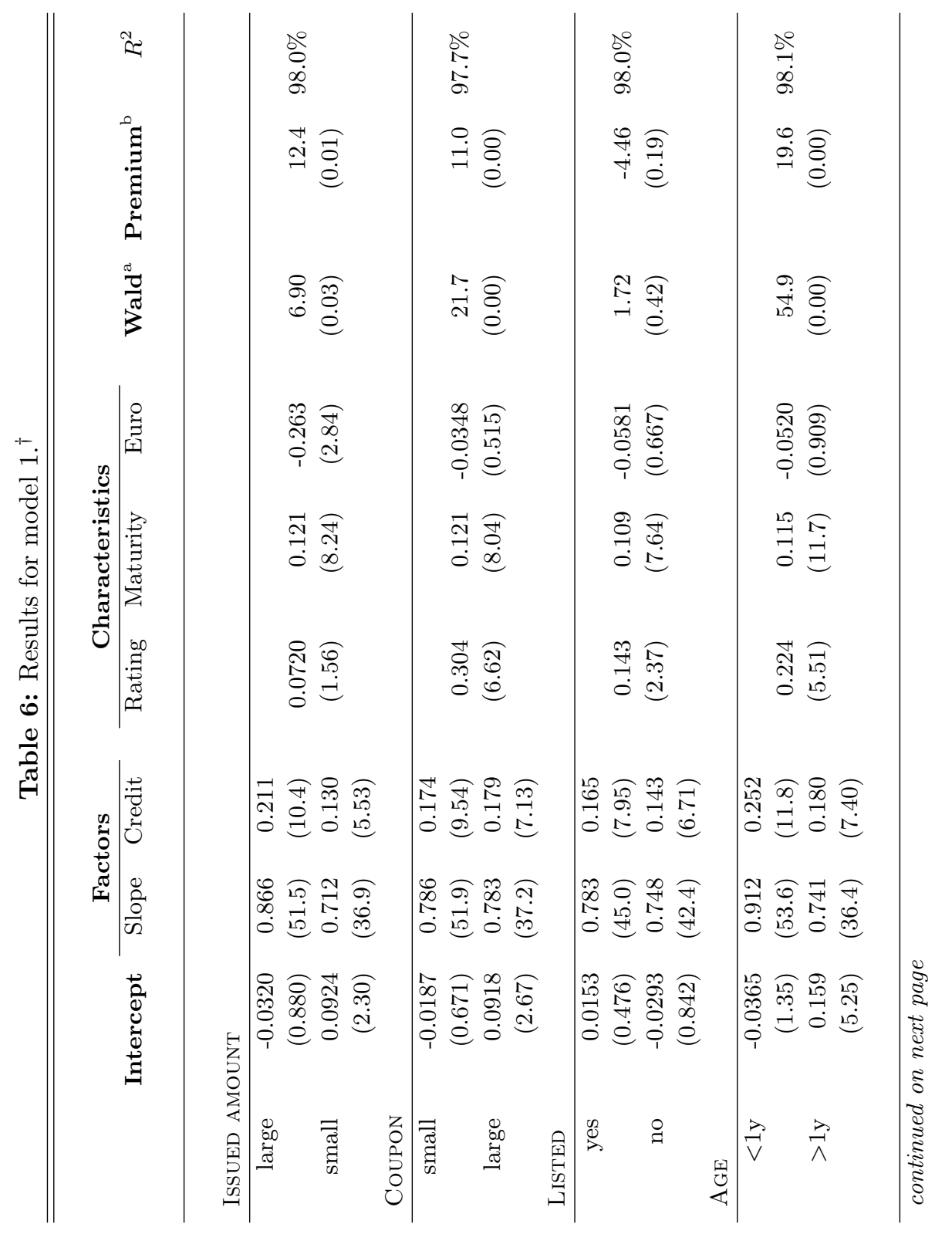




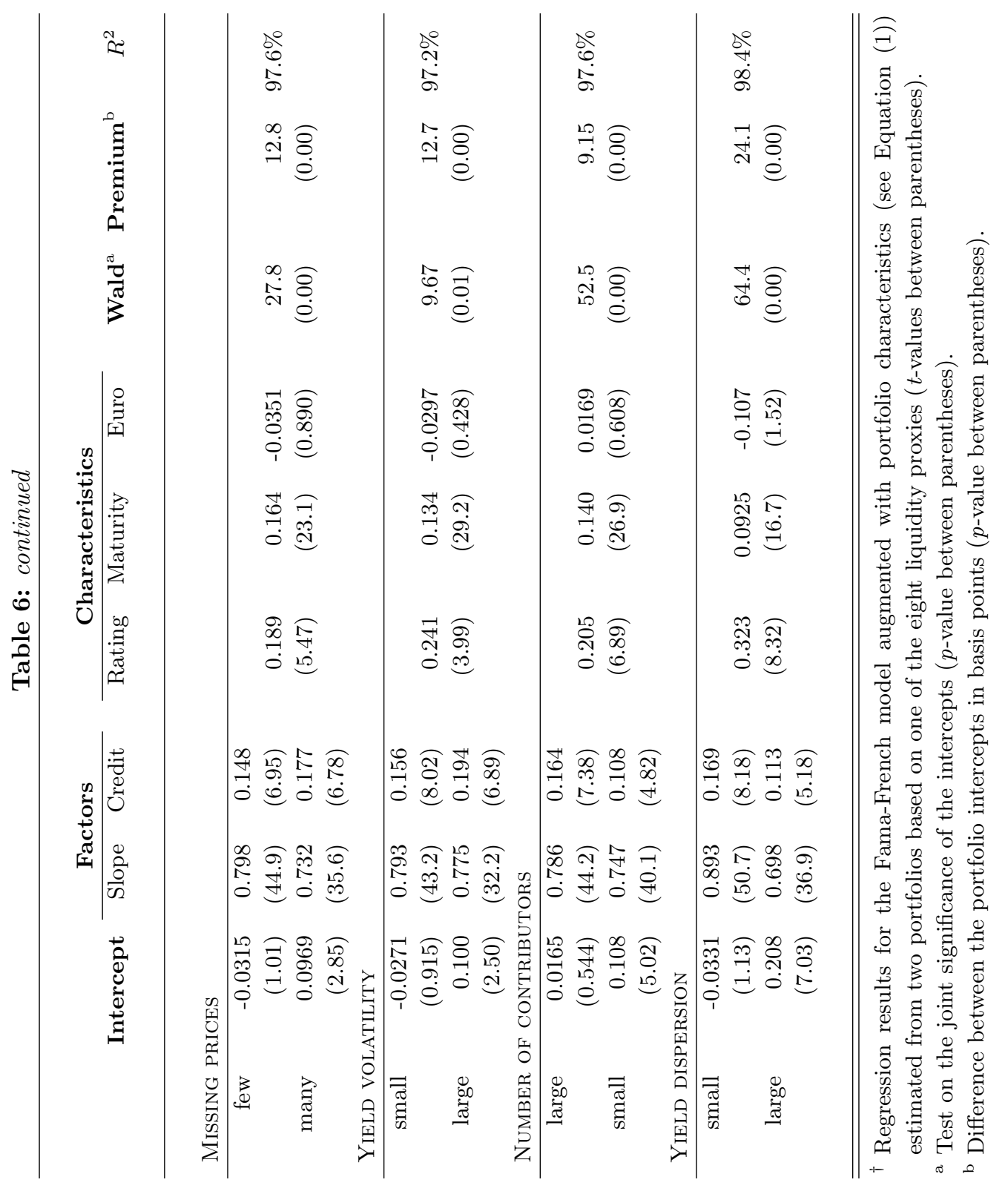




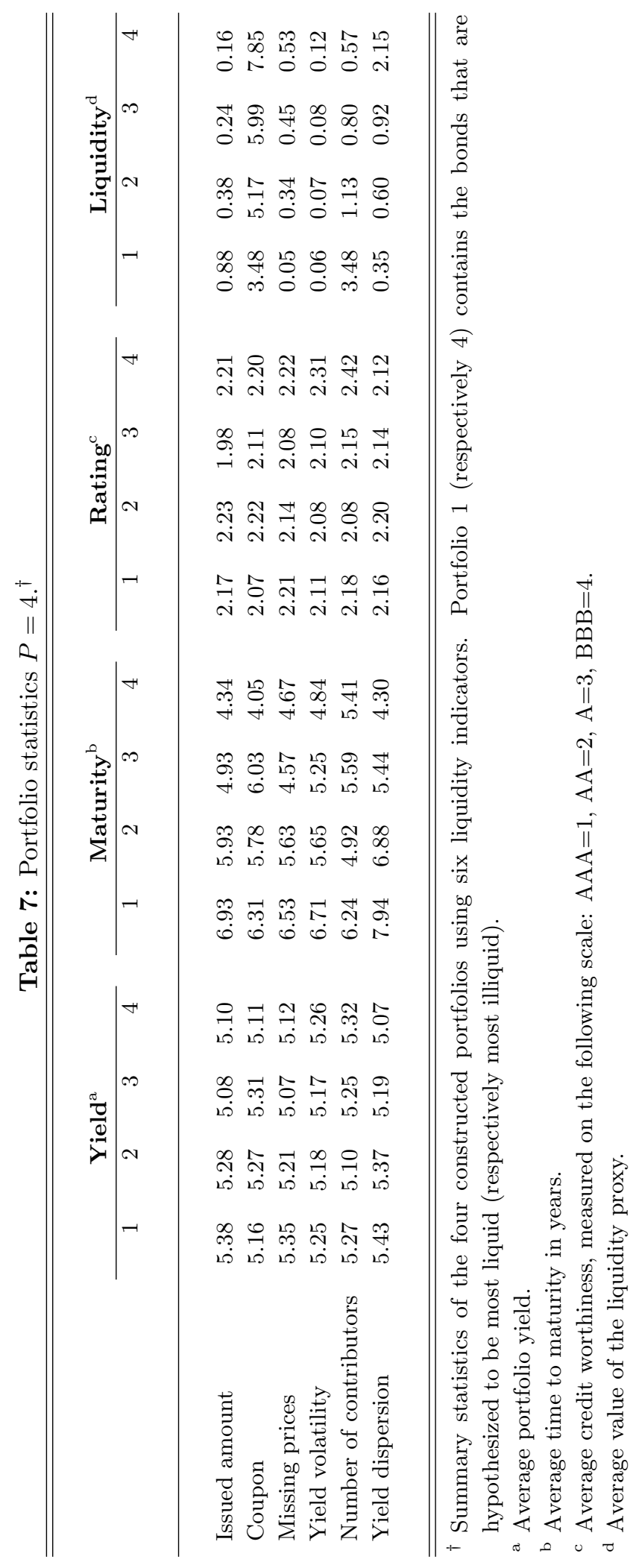


Table 8: Results for model $2 .^{\dagger}$

\begin{tabular}{|c|c|c|c|c|}
\hline & Intercept & Liquidity & Wald $^{\mathrm{a}}$ & $R^{2}$ \\
\hline Issued amount & $\begin{array}{r}0.0316 \\
(1.32)\end{array}$ & $\begin{array}{r}0.338 \\
(11.9)\end{array}$ & $\begin{array}{r}147 \\
(0.00)\end{array}$ & $97.9 \%$ \\
\hline Coupon & $\begin{array}{r}0.0405 \\
(1.71)\end{array}$ & $\begin{array}{r}0.0569 \\
(8.07)\end{array}$ & $\begin{array}{r}65.3 \\
(0.00)\end{array}$ & $97.6 \%$ \\
\hline Missing prices & $\begin{array}{r}0.0894 \\
(3.23)\end{array}$ & $\begin{array}{r}0.357 \\
(7.92)\end{array}$ & $\begin{array}{r}66.2 \\
(0.00)\end{array}$ & $96.3 \%$ \\
\hline Yield volatility & $\begin{array}{r}0.0522 \\
(2.30)\end{array}$ & $\begin{array}{r}1.06 \\
(3.37)\end{array}$ & $\begin{array}{r}17.9 \\
(0.00)\end{array}$ & $96.7 \%$ \\
\hline Number of contributors & $\begin{array}{r}0.102 \\
(3.99)\end{array}$ & $\begin{array}{r}0.00100 \\
(0.173)\end{array}$ & $\begin{array}{r}15.9 \\
(0.00)\end{array}$ & $96.2 \%$ \\
\hline Yield dispersion & $\begin{array}{r}0.0855 \\
(4.26)\end{array}$ & $\begin{array}{r}0.0335 \\
(3.15)\end{array}$ & $\begin{array}{r}28.9 \\
(0.00)\end{array}$ & $97.8 \%$ \\
\hline
\end{tabular}

$\dagger$ Regression results for the Fama-French model augmented with portfolio characteristics and a liquidity variable (see Equation (2)) estimated from four portfolios based on one of six liquidity proxies ( $t$-values between parentheses). The coefficients and $t$-values of the Fama-French factors and the characteristics are omitted for space considerations.

a Test on the joint significance of the intercept and the coefficient of the liquidity variable ( $p$-value between parentheses).

Table 9: Results of the comparison tests. ${ }^{\dagger}$

\begin{tabular}{lccc}
\hline \hline & Adds power & Subsumes & Total \\
& & & \\
\hline & 4 & 1 & 5 \\
Issued amount & 3 & 2 & 5 \\
Coupon & 2 & 1 & 3 \\
Missing prices & 2 & 3 & 5 \\
Yield volatility & 4 & 2 & 6 \\
Number of contributors & 4 & 2 & 6 \\
Yield dispersion & & & \\
& & & \\
\hline
\end{tabular}

$\dagger^{\dagger}$ Results of the pair wise comparisons of six liquidity proxies (see Equation (3)). The table displays the number of times a proxy adds explanatory power to another proxy and the number of times a proxy subsumes another proxy. 